\title{
Hubungan Status Gizi dengan Karies pada Gigi Molar Pertama Bawah Permanen pada Anak Usia 6-8 Tahun di SDN 36 Manado
}

\author{
${ }^{1}$ Avita Aulia \\ ${ }^{1}$ Paulina N. Gunawan \\ ${ }^{2}$ Shirley E. S. Kawengian
}
${ }^{1}$ Program Studi Pendidikan Dokter Gigi Fakultas Kedokteran Universitas Sam Ratulangi Manado
${ }^{2}$ Bagian Ilmu Gizi Fakultas Kedokteran Universitas Sam Ratulangi Manado
Email: avitaaulia13@gmail.com

\begin{abstract}
Caries is the presence of a cavity on the tooth caused by the activity of microorganism on fermented carbohydrate. Nutritional status is resulting from food consumption, which is one of the factors that influence the occurence of dental caries. This study was aimed to obtain the relationship between nutritional status and caries in permanent lower first molar among students of SDN 36 (elementary school) Manado. This was an analytical study using a cross sectional design. There were 48 students at SDN 36 Manado aged 6-8 years in this study obtained by using total sampling technique. We used the nutritional status based on length-for-age and BMI-for-age using the z-scores WHO anthropometrical standards for children aged 5-18 years and examined the oral cavity whether there was caries in permanent lower first molars. The results showed that caries in permanent lower first molars was found in $77.1 \%$ of subjects. Nutritional status based on lengthfor-age showed normal category (83.3\%) and short stature/stunted (16.7\%). The nutritional status based on BMI-for-age showed obese category (22.9\%), overweight $(8.3 \%)$, normal $(60.5 \%)$, wasted $(8.3 \%)$, and severely wasted $(0.0 \%)$. The Fisher's Exact test and the Chi-Square test showed that the relationship between length-for-age and the occurence of caries had a p-value of 1,000 meanwhile the relationship between nutritional status based on BMI-for-age and the occurence of caries had a p-value of 0.024. Conclusion: There was a significant relationship between nutritional status based on BMI-for-age and caries in the permanent lower first molars in children aged 6-8 years at SDN 36 Manado.
\end{abstract}

Keywords: dental caries, permanent lower first molar, nutritional status

\begin{abstract}
Abstrak: Karies adalah adanya rongga pada yang disebabkan oleh aktivitas jasad renik terhadap karbohidrat yang dapat diragikan. Status gizi merupakan keadaan tubuh sebagai akibat konsumsi makanan, yang menjadi salah satu faktor yang dapat memengaruhi proses terjadinya karies gigi. Penelitian ini bertujuan untuk mengetahui hubungan antara status gizi dengan karies gigi molar pertama bawah permanen pada anak usia 6-8 tahun di SDN 36 Manado. Jenis penelitian ialah analitik dengan desain potong lintang. Pengambilan sampel menggunakan teknik total sampling terhadap seluruh siswa di SDN 36 Manado berusia 6-8 tahun pada tahun 2019 yang berjumlah 48 orang. Pada penelitian ini dilakukan pengukuran status gizi TB/U dan IMT/U berdasarkan SD dengan standar baku antropometri WHO untuk anak usia 5-18 tahun serta pemeriksaan rongga mulut untuk melihat ada tidaknya karies pada gigi molar pertama bawah permanen. Hasil pemeriksaan menunjukkan terdapatnya karies pada gigi molar pertama bawah permanen sebesar $77,1 \%$ subyek. Status gizi berdasarkan TB/U didapatkan subyek kategori normal $(83,3 \%)$ dan pendek/stunted $(16,7 \%)$. Status gizi berdasarkan IMT/U didapatkan kategori obesitas $(22,9 \%)$, gemuk $(8,3 \%)$, normal $(60,5 \%)$, kurus $(8,3 \%)$, serta sangat kurus $(0,0 \%)$. Hasil uji Fisher's Exact dan uji Chi-Square menunjukkan untuk TB/U nilai $\mathrm{p}=1,000$ sedangkan untuk IMT/U nilai $\mathrm{p}=0,024$. Simpulan: Terdapat hubungan bermakna antara status gizi berdasarkan IMT/U dengan karies gigi molar pertama bawah permanen pada anak usia 6-8 tahun di SDN 36 Manado.
\end{abstract}

Kata kunci: karies gigi, molar pertama bawah permanen, status gizi 
Kasus karies gigi merupakan salah satu penyakit gigi dan mulut di bidang kedokteran gigi yang banyak dijumpai baik di negara maju maupun di negara berkembang. Global Burden of Disease Study melaporkan bahwa pada tahun 2016 karies gigi permanen merupakan salah satu penyakit dengan prevalensi terbesar di berbagai negara yaitu sebesar 95,0\%. ${ }^{1}$ Hasil Riset Kesehatan Dasar (Riskesdas) tahun 2018 menunjukkan proporsi penduduk Indonesia yang memiliki masalah karies gigi pada kelompok usia 5-9 tahun yaitu sebesar $92,6 \% .^{2}$

Kesehatan gigi dan mulut merupakan bagian dari kesehatan tubuh yang saling memengaruhi. Derajat kesehatan dapat dinilai dengan beberapa indikator, salah satunya yaitu dengan status gizi yang dapat diukur melalui penilaian antropometri. Variabel tinggi badan per umur (TB/U) dan indeks massa tubuh menurut umur (IMT/U) dapat digunakan untuk mengetahui prevalensi status gizi anak sekolah dan remaja serta dapat dikaitkan dengan terjadinya karies gigi. ${ }^{3,4}$

Hasil pemantauan status gizi tahun 2017 menunjukkan prevalensi nasional status gizi anak sekolah dan remaja umur 512 tahun di Indonesia berdasarkan TB/U sebesar $19,4 \%$ untuk anak pendek dan $8,3 \%$ untuk anak sangat pendek serta berdasarkan IMT/U sebesar 7,5\% untuk anak dengan status gizi kurus dan 3,4\% untuk anak dengan status gizi sangat kurus. ${ }^{5}$

Serupa dengan status gizi, karies gigi merupakan kondisi kompleks yang dipengaruhi oleh beberapa faktor (multifaktorial). Studi di luar negeri melaporkan terdapat hubungan antara status gizi dengan karies gigi yang menandakan anak obes menderita karies gigi lebih tinggi daripada anak dengan berat badan normal. ${ }^{6}$ Studi lain menyatakan bahwa tidak terdapat perbedaan berarti skor DMFT/deft pada anak dengan status gizi yang berbeda., 7

Kejadian karies gigi yang banyak terjadi yaitu pada gigi permanen khususnya gigi molar pertama bawah permanen. Penelitian yang dilakukan oleh Kumar et $\mathrm{al}^{9}$ di India pada tahun 2014 menunjukkan bahwa gigi molar pertama bawah permanen memiliki persentase karies gigi sebesar $65,77 \%$. Hal ini terjadi karena bentuk anatomis gigi molar pertama bawah permanen dapat menjadi tempat retensi makanan sehingga berisiko terkena karies gigi, terlebih pada anak-anak yang umumnya gemar mengonsumsi makanan yang manis.

Sekolah Dasar Negeri (SDN) 36 Manado merupakan salah satu sekolah dasar yang terletak di kelurahan Bahu yang dekat dengan pusat perekonomian kota Manado. Dilihat dari kebiasaannya seharihari, siswa SDN 36 Manado mempunyai kebiasaan mengonsumsi jajanan manis yang banyak dijajakan di sekitar sekolah, yang diasumsikan akan memengaruhi status gizinya. Lokasinya yang dekat dengan kampus peneliti mempermudah proses pemantauan upaya preventif dan promotif yang dapat dilaksanakan setelah hasil penelitian ini diperoleh.

Penelitian ini bertujuan untuk mengetahui hubungan status gizi dengan karies pada gigi molar pertama bawah permanen pada anak usia 6-8 tahun di SDN 36 Manado.

\section{METODE PENELITIAN}

Jenis penelitian ini ialah analitik dengan desain potong lintang. Penelitian dilaksanakan di SDN 36 Manado Jl. Kampus Timur-Kleak, Kelurahan Bahu, Kecamatan Malalayang, Kota Manado, Provinsi Sulawesi Utara pada bulan Februari-April 2019.

Populasi penelitian ini yaitu seluruh siswa di SDN 36 Manado yang berusia 6-8 tahun pada tahun 2019 berjumlah 58 orang. Metode pengambilan sampel yang digunakan ialah metode total populasi yang memenuhi kriteria inklusi berjumlah 48 orang. Sebanyak 10 siswa dieksklusi karena orang tua siswa tidak mengizinkan untuk diikutsertakan dalam penelitian.

Pengumpulan data dilakukan dengan pemeriksaan langsung terhadap subyek penelitian, yaitu pengukuran tinggi badan dan berat badan, lalu dikategorikan berdasarkan kategori usia pada TB/U dan IMT/U 
untuk menilai status gizi. Pemeriksaan karies ditujukan pada gigi molar pertama bawah permanen. Data yang dikumpulkan yakni daftar nama serta tanggal lahir siswa yang termasuk dalam kriteria inklusi untuk dijadikan sampel.

Pengisian informed consent dilakukan oleh orang tua siswa. Pengukuran berat badan menggunakan timbangan badan analog dan pengukuran tinggi badan dinilai menggunakan microtoise. Hasil ukurnya dikategorikan menjadi $\mathrm{TB} / \mathrm{U}$ dua kategori dan IMT/U lima kategori. Kategori untuk TB/U yaitu normal -2 SD $\mathrm{s} / \mathrm{d}-1 \quad \mathrm{SD}$; pendek/stunted -3 SD s/d <-2 SD. Kategori untuk status gizi berdasarkan IMT/U, yaitu obesitas >2 SD; gemuk >1 SD s/d 2 SD; normal -2 SD s/d 1 SD; kurus -3 SD s/d <-2 $\mathrm{SD}$; dan sangat kurus <-3 SD. ${ }^{10}$

Pemeriksaan karies gigi dilakukan dengan menggunakan bantuan pencahayaan dan kaca mulut untuk melihat gigi molar pertama bawah permanen. Jika pada gigi tersebut terdapat karies maka lakukan pemeriksaan sondasi. Gigi dicatat terdapat karies bila ketika permukaannya ditelusuri dengan sonde maka akan tersangkut atau jika dilihat dengan penglihatan tajam maka gigi terlihat berwarna coklat kehitaman. Yang terdapat karies gigi diberi tanda $(\sqrt{ })$ dan yang tidak terdapat karies gigi diberi tanda (X) pada formulir pemeriksaan status gizi dan karies gigi.

Pengolahan data dilakukan menggunakan Statistical Package for the Social Sciences (SPSS) versi 22 untuk Windows. Analisis digunakan untuk memperoleh gambaran pada masing-masing variabel dalam bentuk tabel distribusi frekuensi. Analisis bivariat menggunakan uji statistik Fisher's Exact dan Chi-Square untuk menguji hubungan antara status gizi dengan karies pada gigi molar pertama bawah permanen pada anak usia 6-8 tahun.

\section{HASIL PENELITIAN}

Penelitian ini dilaksanakan di SDN 36 Manado, yang merupakan salah satu sekolah dasar di Kota Manado. Subjek penelitian ini ialah siswa SDN 36 Manado kelas I dan II berusia 6-8 tahun sebanyak 48 orang. Subyek berjenis kelamin laki-laki sebanyak 24 siswa $(50,0 \%)$ dan yang berjenis kelamin perempuan sebanyak 24 siswa $(50,0 \%)$.

Tabel 1 menunjukkan bahwa dari 48 subyek penelitian, yang terbanyak ialah berusia 7 tahun $(47,9 \%)$ dan yang paling sedikit berusia 6 tahun $(14,6 \%)$.

Tabel 1. Distribusi subyek berdasarkan usia

\begin{tabular}{ccc}
\hline $\begin{array}{c}\text { Usia } \\
\text { (tahun) }\end{array}$ & n & \% \\
\hline 6 & 7 & 14,6 \\
7 & 23 & 47,9 \\
8 & 18 & 37,5 \\
Total & 48 & 100 \\
\hline
\end{tabular}

Hasil pengisian lembar identitas diri subyek penelitian menunjukkan siswa dengan saudara berjumlah 2 orang yang terbanyak pada penelitian ini $(45,8 \%)$ dan yang paling sedikit yaitu siswa dengan jumlah saudara 3 orang $(8,3 \%)$.

Untuk karakteristik keluarga, terdapat tiga jenis pekerjaan ayah dan ibu subyek. Pekerjaan ayah yang terbanyak yaitu swasta/wiraswasta $(52,1 \%)$ dan yang paling sedikit honorer/buruh/pensiunan (12,5\%), sedangkan pekerjaan ibu yang terbanyak yaitu sebagai ibu rumah tangga (IRT) $(58,3 \%)$. Distribusi berdasarkan pendidikan terakhir ayah dan ibu subyek memperlihatkan pendidikan terakhir ayah dan ibu terbanyak ialah lulusan SMA $(50,0 \%$ dan $66,7 \%$ ).

Hasil pemeriksaan status gizi dilakukan dengan menghitung TB/U dan IMT/U menggunakan rumus IMT. Tabel 2 menunjukkan bahwa subyek terbanyak mempunyai status gizi normal berdasarkan $\mathrm{TB} / \mathrm{U}$ $(83,3 \%)$ dan yang paling sedikit yaitu yang pendek/stunted $(16,7 \%)$.

Tabel 2. Distribusi subyek berdasarkan status gizi $\mathrm{TB} / \mathrm{U}$

\begin{tabular}{lcc}
\hline Status gizi & n & \% \\
\hline Normal & 40 & 83,3 \\
Pendek/stunted & 8 & 16,7 \\
Total & 48 & 100 \\
\hline
\end{tabular}


Tabel 3 menunjukkan bahwa subyek dengan status gizi berdasarkan IMT/U normal menempati posisi tertinggi $(60,5 \%)$ dan posisi terendah ditempati yang berstatus gizi sangat kurus $(0,0 \%)$.

Tabel 3. Distribusi subyek berdasarkan status gizi IMT/U

\begin{tabular}{lcc}
\hline Status gizi & n & \% \\
\hline Obesitas & 11 & 22,9 \\
Gemuk & 4 & 8,3 \\
Normal & 29 & 60,5 \\
Kurus & 4 & 8,3 \\
Sangat & 0 & 0,0 \\
Kurus & 48 & 100 \\
Total & \\
\hline
\end{tabular}

Hasil pemeriksaan karies pada gigi molar petama bawah permanen dilakukan dengan melihat ada tidaknya rongga pada gigi terbesar di rahang bawah yang diperiksa dengan menggunakan alat kaca mulut, sonde, alat penerang, serta gigi diisolasi menggunakan chip blower, cotton roll, dan cotton pellet agar tetap kering. Gigi dikatakan karies jika ada bercak putih atau berwarna coklat kehitaman jika dilihat dengan penglihatan tajam dan melalui pemeriksaan sondasi pada permukaan oklusal maka sonde akan tersangkut. Sampel dengan karies pada elemen gigi 46 atau pada gigi molar pertama kanan bawah permanen menempati posisi tertinggi karies sebesar $77,1 \%$ dan yang terendah karies ditempati karies pada gigi 36 atau gigi molar pertama kiri bawah permanen sebesar $66,7 \%$.

Tabel 4 menunjukkan sampel dengan karies pada gigi molar pertama bawah permanennya yaitu sebesar $77,1 \%$ dan yang terendah pada sampel yang tidak terdapat karies pada gigi molar pertama bawah permanennya sebesar $22,9 \%$.

Tabel 4. Distribusi subyek berdasarkan ada tidaknya karies pada gigi molar pertama bawah permanen

\begin{tabular}{lcc}
\hline Karies & $\mathbf{n}$ & $\mathbf{\%}$ \\
\hline Ya & 37 & 77,1 \\
Tidak & 11 & 22,9 \\
Total & 48 & 100 \\
\hline
\end{tabular}

Tabel 5 menunjukkan bahwa subyek penelitian yang menempati posisi tertinggi yaitu yang terdapat karies pada gigi molar pertama bawah permanen dengan status gizi TB/U kategori normal $(77,5 \%)$ dan yang menempati posisi terendah yaitu subyek yang tidak terdapat karies pada gigi molar pertama bawah permanen dengan status gizi TB/U kategori normal (22,5\%).

Berdasarkan uji Fisher's Exact yang dilakukan, didapatkan signifikansi nilai $\mathrm{p}=$ 1,000 yang menunjukkan tidak terdapat hubungan bermakna antara status gizi berdasarkan TB/U dengan karies gigi molar pertama bawah permanen pada anak usia 68 tahun di SDN 36 Manado. Juga diperoleh nilai $\quad \mathrm{OR}=1,148 \quad(95 \% \quad \mathrm{CI}=0,197-6,700)$ yang berarti seseorang yang termasuk kategori status gizi berdasarkan TB/U normal berisiko 1,148 kali lebih besar mengalami karies pada gigi molar pertama bawah permanen dibandingkan dengan yang memiliki kategori status gizi berdasarkan TB/U pendek/stunted.

Tabel 5. Hubungan antara status gizi berdasarkan TB/U dengan karies pada gigi molar pertama bawah permanen pada anak usia 6-8 tahun di SDN 36 Manado

\begin{tabular}{|c|c|c|c|c|c|c|c|c|}
\hline \multirow{3}{*}{$\begin{array}{c}\text { Status Gizi } \\
\text { TB/U }\end{array}$} & \multicolumn{6}{|c|}{ Karies Gigi } & \multirow[b]{2}{*}{ Nilai p } & \multirow{3}{*}{$\underset{\text { CI }}{\text { OR dengan }} 95 \%$} \\
\hline & \multicolumn{2}{|c|}{ Karies } & \multicolumn{2}{|c|}{ Tidak karies } & \multicolumn{2}{|c|}{ Total } & & \\
\hline & $\mathrm{n}$ & $\%$ & $\mathrm{n}$ & $\%$ & $\mathrm{n}$ & $\%$ & & \\
\hline Normal & 31 & 77,5 & 9 & 22,5 & 40 & 100 & & 1,148 \\
\hline Pendek/stunted & 6 & 75,0 & 2 & 25,0 & 8 & 100 & & $(0,197-6,700)$ \\
\hline
\end{tabular}


Tabel 6. Hubungan antara status gizi berdasarkan IMT/U dengan karies pada gigi molar pertama bawah permanen pada anak usia 6-8 tahun di SDN 36 Manado

\begin{tabular}{lccccccc}
\hline \multirow{2}{*}{$\begin{array}{c}\text { Status Gizi } \\
\text { IMT/U }\end{array}$} & \multicolumn{6}{c}{ Karies } & \multicolumn{2}{c}{ Tidak Karies } & \multicolumn{2}{c}{ Total } & \\
\cline { 2 - 7 } \multicolumn{1}{c}{} & $\mathrm{n}$ & $\%$ & $\mathrm{n}$ & $\%$ & $\mathrm{n}$ & $\%$ & \multirow{2}{*}{ Nilai p } \\
\hline Obesitas & 11 & 100 & 0 & 0,0 & 11 & 100 & \\
Gemuk & 3 & 75,0 & 1 & 25,0 & 4 & 100 & 0,024 \\
Normal & 22 & 75,9 & 7 & 24,1 & 29 & 100 & \\
Kurus & 1 & 25,0 & 3 & 75,0 & 4 & 100 & \\
\hline
\end{tabular}

Tabel 6 menunjukkan bahwa posisi tertinggi ditempati subyek dengan karies pada gigi molar pertama bawah permanen dengan status gizi IMT/U kategori obesitas sebesar $100 \%$, sedangkan posisi terendah ditempati subyek yang tidak mengalami karies pada gigi molar pertama bawah permanen dengan status gizi IMT/U kategori obesitas sebesar $0,0 \%$. Hasil uji Chi-Square mendapatkan nilai $\mathrm{p}=0,024$ yang menunjukkan adanya hubungan bermakna antara status gizi berdasarkan IMT/U dengan karies pada gigi molar pertama bawah permanen pada anak usia 68 tahun di SDN 36 Manado.

\section{BAHASAN}

Penelitian ini dilakukan di SDN 36 Manado melalui pemeriksaan objektif pada 48 siswa usia 6-8 tahun. Hasil penelitian mendapatkan sebanyak $77,1 \%$ siswa mempunyai karies pada gigi molar pertama bawah permanen, dengan persentase karies pada gigi 46 sebesar $77,1 \%$ dan pada gigi 36 sebesar $66,7 \%$. Hal ini dapat terjadi karena bentuk anatomis gigi molar pertama bawah permanen dapat menjadi tempat retensi makanan sehingga berisiko terkena karies gigi. Permukaan oklusal gigi molar pertama bawah permanen memiliki pit dan fisur yang dalam, sehingga dapat menjadi tempat terselipnya sisa makanan yang akan menjadi plak dan lokasi perkembangan karies. Akumulasi dan retensi plak dapat meningkatkan kemungkinan terjadinya proses fermentasi karbohidrat oleh bakteri asidogenik yang dapat memroduksi dan menyimpan asam organik pada plak di permukaan gigi yang berkemampuan untuk menghancurkan kristal apatit gigi sehingga terjadi karies gigi. Hasil ini selaras dengan penelitian yang dilakukan Kumar et $\mathrm{al}^{9}$ di India yang menunjukkan gigi molar pertama bawah permanen memiliki persentase karies sebesar $65,77 \% .^{9,11}$

Hasil penelitian ini mendapatkan persentase kasies pada gigi molar pertama bawah permanen lebih besar pada anak usia 8 tahun, yaitu $89,5 \%$. Pada anak usia 8 tahun, gigi molar pertama bawah permanen merupakan gigi permanen yang pertama kali erupsi dalam rongga mulut sehingga lebih terbuka ke lingkungan mulut untuk periode waktu yang lebih lama. Karies gigi tidak muncul dalam hitungan hari atau minggu melainkan dalam bulan atau tahun. Karies gigi merupakan proses patologik pada jaringan keras gigi, yang disebabkan oleh empat faktor yang terjadi secara bersamaan dengan faktor waktu yang sangat menentukkan proses terjadinya karies gigi. Hal ini dapat dikaitkan dengan peningkatan terjadinya karies gigi seiring dengan bertambahnya usia seseorang, yang sesuai dengan penelitian yang dilakukan oleh Togoo et al ${ }^{12}$ di Arab Saudi.

Berdasarkan hasil penelitian ini mengenai ada tidaknya karies pada gigi molar pertama bawah permanen menurut jenis kelamin pada anak usia 6-8 tahun di SDN 36 Manado, didapatkan siswa lakilaki dan perempuan sama-sama mengalami karies, yaitu masing-masing sebesar 75,0\%. Hal ini sejalan dengan penelitian yang dilakukan Homata et $\mathrm{al}^{13}$ di Yunani yang menunjukkan baik laki-laki dan perempuan memiliki risiko yang sama terhadap terjadinya karies gigi. 
Hasil penelitian status gizi TB/U dengan karies pada gigi molar pertama bawah di SDN 36 Manado menunjukkan tidak terdapat hubungan bermakna antara status gizi berdasarkan TB/U dengan karies pada gigi molar pertama bawah permanen pada anak usia 6-8 tahun di SDN 36 Manado $(p=1,000>0,05)$. Berbeda halnya dengan penelitian status gizi IMT/U dengan karies pada gigi molar pertama bawah yang menunjukkan adanya hubungan bermakna antara status gizi berdasarkan IMT/U dengan karies pada gigi molar pertama bawah permanen pada anak usia 6-8 tahun di SDN 36 Manado, yang dinyatakan oleh hasil uji Chi-Square $(\mathrm{p}=0,024 \leq 0,05)$. Hal ini dapat terjadi karena karies gigi lebih dipengaruhi oleh konsumsi gula atau karbohidrat yang berlebih dalam frekuensi yang lama. Konsumsi karbohidrat dapat dipantau melalui berat badan dan tinggi badan atau melalui status gizi pada saat ini yang dapat digambarkan melalui IMT/U.

Penelitian mengenai karies menjadi suatu tantangan karena bersifat multifaktorial yang dipengaruhi antara lain oleh diet dan status sosial ekonomi. Pada penelitian ini ditemukan subyek yang mengalami karies gigi molar pertama bawah permanen terbanyak pada status gizi kategori obesitas sebesar $100 \%$. Penelitian ini juga didukung oleh studi yang dilakukan oleh Vázquez-Nava et $\mathrm{al}^{6}$ di Meksiko dan Goodarzi et al di Tehran yang melaporkan bahwa terdapat hubungan antara status gizi dengan karies gigi yang menandakan anak obesitas dan normal menderita karies gigi lebih tinggi. ${ }^{6,16}$ Frekuensi konsumsi karbohidrat seperti gula dengan kalori tinggi dapat memengaruhi status gizi pada saat ini yang dapat digambarkan melalui IMT/U. Frekuensi konsumsi karbohidrat umumnya menjadi penyebab timbulnya karies serta obesitas pada anak, terlebih jika dihubungkan dengan tingginya konsumsi makanan kariogenik sehingga anak dapat mengalami obesitas serta karies gigi secara bersamaan.

Berdasarkan survei peneliti, didapatkan bahwa hanya sedikit anak yang membawa bekal ke sekolah dan banyak yang membeli jajanan di kantin sekolah serta jajanan yang tersedia diluar sekolah. Makanan jajanan yang paling banyak dijual di SDN 36 Manado, yaitu makanan bergula seperti aneka makanan ringan (permen, wafer, biskuit), minuman jeruk seduh, mi instan dalam cup, nasi kuning, dan bakso tusuk. Selain itu, terdapat dua minimarket di dekat SDN 36 Manado yang menyediakan berbagai macam jajanan. Semua jajanan ini akan memicu terjadinya karies gigi khususnya karies gigi molar pertama bawah permanen pada anak usia 6-8 tahun di SDN 36 Manado.

Status sosial ekonomi seperti pendapatan kelurga diketahui berperan dalam timbulnya karies serta obesitas pada anak. Dalam penelitian ini diketahui pekerjaan ayah yang paling banyak yaitu bekerja swasta/wiraswasta $(52,1 \%)$ dan yang paling sedikit honorer/buruh/pensiunan (12,5\%). Pendapatan keluarga yang cukup dapat berperan dalam timbulnya karies gigi serta obesitas pada anak, karena makanan olahan yang banyak mengandung karbohidrat sederhana/tinggi gula dan tinggi kandungan lemak menjadi lebih mudah untuk diakses. Karies pada anak juga berhubungan erat pada kontrol orang tua terhadap konsumsi makanan dan perilaku anak dalam menjaga kesehatan gigi dan mulut. Dalam hal ini, tingkat pendidikan orang tua berpengaruh dalam kesadaran dan kontrol perilaku anak dalam menjaga kesehatan gigi dan mulut. ${ }^{17}$ Pada penelitian ini, diketahui pendidikan terakhir baik ayah dan ibu subyek yang paling banyak yaitu lulusan SMA sebesar $50,0 \%$ dan $66,7 \%$. Hal ini sejalan dengan penelitian di luar negeri yang dilakukan oleh Poopola et al $^{18}$ di Ibadan yang menyatakan bahwa anak-anak yang berasal dari kelas sosial atas dan menengah mempunyai prevalensi karies gigi yang lebih tinggi dibanding anak-anak dari kelas sosial rendah. Poopola et al juga menyatakan bahwa di beberapa negara di Afrika, karies gigi dikaitkan dengan peningkatan konsumsi gula dari makanan dan minuman, sementara itu konsumsi gula tetap rendah di negara ekonomi rendah. 
Penelitian ini berbeda dengan penelitan di Indonesia yang dilakukan oleh Nurlaila et al $^{19}$ di Kecamatan Karangantu, Provinsi Banten, yang menyatakan bahwa tidak terdapat hubungan bermakna antara status gizi dengan karies gigi pada murid-murid berusia 9-14 tahun di Sekolah Dasar Kecamatan Karangantu, Provinsi Banten. Nurlaila et al menyatakan bahwa keadaan ini lebih disebabkan karena makanan kariogenik dapat berdampak langsung sebagai penyebab terjadinya penyakit karies gigi apabila didukung oleh keadaan ketahanan gigi yang rendah, keadaan jumlah saliva yang kurang dari normal dan bersifat kental, kemudian lamanya waktu menempelnya sisa makanan dan plak yang tidak dibersihkan.

Limitasi penelitian ini, yaitu tidak dapat ditentukan apakah status gizi berdasarkan IMT/U pada anak usia 6-8 tahun di SDN 36 Manado yang memengaruhi terjadinya karies gigi terlebih dahulu ataukah karies gigi yang ada terjadi karena dipengaruhi oleh status gizi berdasarkan IMT/Unya terlebih dahulu. Hal ini disebabkan karena keterbatasan waktu penelitian.

\section{SIMPULAN}

Berdasarkan hasil penelitian ini dapat disimpulkan bahwa terdapat hubungan bermakna antara status gizi berdasarkan IMT/U dengan karies pada gigi molar pertama bawah permanen pada anak usia 68 tahun di SDN 36 Manado.

\section{SARAN}

Dinas kesehatan dan/atau pihak SDN 36 Manado perlu melaksanakan program promotif dan preventif yang interaktif untuk anak di SDN 36 Manado agar dapat terciptanya perilaku serta kebiasaan yang baik untuk menjaga kesehatan gigi dan mulut serta kepada masing-masing anak dan masing-masing orang tua/wali anak untuk memeriksakan gigi anak minimal 6 bulan sekali, rutin memantau berat badan normalnya, serta dilakukan perawatan kuratif dan rehabilitatif untuk anak yang gigi molar pertama bawah permanennya telah terkena karies untuk mencegah meluasnya karies lebih lanjut.

Dikarenakan keterbatasan waktu peneliti, diharapkan adanya penelitian lanjut mengenai hubungan antara status gizi dengan karies gigi molar pertama bawah permanen pada anak dengan menggunakan standar antropometri lainnya atau dengan melakukan uji statistik lebih lanjut misalnya menggunakan uji regresi untuk mendapatkan hasil yang lebih rinci.

\section{DAFTAR PUSTAKA}

1. Global Burden of Disease Study. Global, regional, and national incidence, prevalence, and years lived with disability for 328 diseases and injuries for 195 countries, 1990-2016: a systematic analysis for the Global Burden of Disease Study 2016. Elsevier. 2017;390:1229.

2. Badan Penelitian dan Pengembangan Kesehatan. Laporan nasional Riskesdas 2018. Jakarta: Kemenkes RI; 2018. p.181-207.

3. Trihono, Atmarita, Tjandrarini DH, Irawati A, Utami NH, Tejayanti T, et al. Pendek (stunting) di Indonesia, Masalah dan Solusinya. Jakarta: Balitbangkes, 2015; p. 19.

4. World Health Organization. WHO reference 2007: Growth reference data for 5-19 years. [Internet] 2013. [cited 2019 Feb 21]. Available from: URL: http://www. who.int/growthref/en/

5. Direktorat Gizi Masyarakat. Buku Saku Pemantauan Status Gizi Tahun 2017. Jakarta: Kemenkes RI, 2017; p. 61-2.

6. Vázquez-Nava F, Vázquez-Rodríguez EM, Saldívar-González AH. Association between obesity and dental caries in a group of preschool children in Mexico. J Public Health Dent. 2010;70(2);12430.

7. Frias-Bulhosa J, Barbosa PE. Association between body mass index and caries among 13-year-old population in Castelo de Paiva. Med Dent e Cirurgia Maxilo. 2015;6(1):3-8.

8. D'Mello G, Chia L, Hamilton SD, Thomson WM, Drummon BK. Childhood obesity and dental caries among paediatric dental clinic attenders. Int $\mathbf{J}$ Paediatr Dent. 2011;21(3):217-22. 
9. Kumar A, Dutta S, Namdev R. Prevalence and relationship between dental caries, diet and nutrition, socioeconomic status, and oral hygiene habits in children using laser fluorescence device (Diagnodent). J Oral Health Comm Dent. 2014;8(1):16-23.

10. Direktorat Jenderal Kesehatan Masyarakat. Rapor kesehatanku buku catatan kesehatan peserta didik tingkat SD/MI. Jakarta: Kemenkes RI, 2018; p. 44-7.

11. Kidd EAM, Bechal SJ. Dasar-dasar Karies Penyakit dan Penanggulangannya. Alih bahasa Sumawinata N, Faruk S. Jakarta: EGC, 1991; p. 1-4,9,22.

12. Togoo R, Yaseen S, Zakirulla M, Al Garni F, Khorage A, Meer A. Prevalence of first permanent molar caries among 7 10 years old school Going boys in Abha city, Saudi Arabia. J Int Oral Health. 2011;3:29-34.

13. Homata EM, Kounari HK, Margaritis V. Gender differences in oral health status and behavior of Greek dental student: a meta-analysis of 1981, 2000, and 2010 data. J Int Soc Prev Comm Dent. 2016;6(1):60-8.

14. Rao A, Rao A, Shenoy R. Principles and
Practice of Pedodontics (3rd ed). In: Rao A, editor. New Delhi: Jaypee Brothers Medical Publishers, 2012; p. 103, 175, 180,184-5.

15. John J. Textbook of Preventive and Community Dentistry: Public Health Dentistry (3rd ed). New Delhi: CBS Publishers and Distributors, 2017; p.183-218.

16. Goodarzi A, Heidarnia A, Tavafian SS, Eslami M. Association between dental caries and body mass index-for-age among 10-12-year-old female students in Tehran. Int J Prev Med. 2019;10:28.

17. Magdalena I. Dasar-dasar Ilmu Gizi Dalam Keperawatan. Yogyakarta: Pustaka Baru Press, 2017; p. 19,93,147-8.

18. Popoola BO, Denyole OO, Iyun OI. Influence of parental socioeconomic status on caries prevalence among children seen at the university college hospital, Ibadan. Ann Ib Postgrad Med. 2013;11(2):81-6.

19. Nurlaila AM, Herwati D, Darwita RR. Hubungan status gizi dengan karies gigi pada murid-murid di sekolah dasar kecamatan Karangantu. Ina J of Dent. 2005;12(1):5-9. 